\title{
Actuator and/or Sensors Integration by Additive Manufacturing for Intelligent Mechanical Applications
}

\author{
Patrícia Freitas Rodrigues ${ }^{1 *}$, Hélder Cordeiro ${ }^{2}$, Francisco Cruz $^{1}$ and Maria Teresa Vieira ${ }^{1 *}$ \\ ${ }^{1}$ Department of Mechanical Engineering, University of Coimbra, Portugal \\ ${ }^{2}$ Moldes RP, Portugal
}

*Corresponding author: Patrícia Freitas Rodrigues and Maria Teresa Vieira, Mechanical Engineering Department, CEMMPRE, University of Coimbra, Portugal.

Received Date: February 01, 2021

Published Date: February 22, 2021

\begin{abstract}
In the last decennia, many applications of functional materials based on shape memory alloys have been identified, designed, modeled, and tested. Among them, the NiTi shape memory alloys allowed the development of actuator and /or sensor devices for engineering and medical fields based on their shape memory and super elastic characteristics. Applications as actuator/sensor are due to the detection almost instantly of the induced phase transformations. A succinct approach about NiTi as actuator and/or sensor integration in low melting temperature parts/system or devices is the target of the summarized review.
\end{abstract}

Keywords: Shape memory alloy (SMA); NiTi; Actuator; Sensor

Abbreviations: SMA: Shape memory alloys; SE: Super elasticity; SME: Shape memory effect; SIM: Stress-induced martensitic transformation; TIM: Thermal-induced martensite transformation

\section{Mini Review}

Shape memory alloys (SMA) are a group of metallic alloys that have attracted much interest as a functional material in a myriad of engineering fields, as active, adaptive, or intelligent structures. These binary compounds present unique properties besides shape memory effect (SME), super elasticity (SE). Among SMA, the NiTi (Nitinol) is the most relevant intermetallic compound due to its functional and excellent mechanical properties [1-2]. The unforeseen functional properties of SMA are due to a reversible martensitic transformation between a stable high-temperature austenitic phase (B2) and low-temperature martensitic phase (B19'). The martensitic transformation can occur directly (B2 $\leftrightarrow B 19$ ) or via R-phase [3]. The super elasticity results from the stress-induced martensitic transformation (SIM) between austenite and martensite[4,5]. Moreover, the shape memory effect is also caused by thermal-induced martensite transformation (TIM) [3]. This behavior lets to their application as actuator and/or sensor, because their structures may detect the mechanical stresses and thermal changes around them and reply almost instantly to the external variation [1-7].

There are several SMA actuator, sensor, and actuator/sensor solutions. Although NiTi alloy is usually used as wire (micrometric and millimetric diameters), bias spring-type actuators provide many advantages, such as significant force output/motion, compact size, high work output, and easy design. These systems could be applied in adjusting wing aircrafta, where the basic problem is to design a SMA actuator system with the required force output, which will generate a specific movement [8]. Depending on the size of parts and the matrix material properties the design could require several NiTi springs as actuators.

The NiTi alloy as a wire sensor can be essential to self-healing systemb to detect cracks during the part applications [9]. This is 
due to the typical characteristic of NiTi of having an excellent linear relationship of electrical resistivity during the martensitic transformation in/from austenite as a function of stress applied in the super elastic field.

Actually, the current research challenge is integrating the SMA wires or springers as actuator and/or sensor in different alloy matrixes, where the melting temperature is lower than the temperature where the NiTi degradation is possible. Indirect additive manufacturing, as material extrusion technology (MEX), could ensure a good performance after processing stages (shaping, debinding and sintering). The adhesion efficiency, between sensor and matrix, can be highlighted by X-ray microtomography, one of the most attractive technique to evaluate the quality of adhesion between matrix and sensor [10].

In practice, NiTi SMA actuators react to temperature changes with a shape change; thus, they can be considered sensor/actuator systems [5]. To use the SMA as both an actuator/sensor provides enormous advantages in cost reduction and optimization of several parts/systems/devices. The microelectromechanical systems (MEMS) can use this advantage by phase transition into NiTi thin films, to apply as pressure gauge (sensor) and react by electrical behavior (actuator) to assure sealing, as well as security of the system through smaller design, due to its high recoverable strain and output forces [11]. The challenge here is to design the NiTi thin films with the required thickness to assure the properties and alloy composition [9-12].

The response of an SMA actuator/sensor in different applications can be significantly affected by several factors, such as: alloy composition, part/system/device geometry, actuation temperature, application conditions, and processing parameters. Thus, the rigorous material investigation is mandatory. However, it is impossible to deny that it is a versatile and promising material.

a4DComposite - Moldação inteligente de componentes 4D baseados em ligas com memória de forma embebidas em carbono pré-impregnado com termoplástico

bCrackFree - Towards self-repairing metallic alloys

\section{Acknowledgment}

This work was financially supported by: Project PTDC/CTMCTM/29101/2017 - POCI-01-0145-FEDER-029101 funded by FEDER funds through COMPETE2020 - Programa Operacional Competitividade e Internacionalização (POCI) and by national funds (PIDDAC) through FCT/MCTES, and Project POCI-01-0247FEDER-033758 funded by Agência Nacional de Inovação, S.A. PT2020-SII\&DT - Copromoção.

This research was also supported by FEDER funds through the program COMPETE - Programa Operacional Factores de Competitividade, and by national funds through FCT Fundação para a Ciência e a Tecnologia, under the project UIDB/ EMS $/ 00285 / 2020$.

\section{Conflict of Interest}

No conflict of interest

\section{References}

1. H Funakubo (1987) Shape Memory Alloys. Gordon and Breach Science Publishers, New York, USA.

2. T Saburi (1998) Ti-Ni Shape Memory Alloys. In: Shape Memory Materials. In: Otsuka, K. WCM (editor) Shape Mem Mater. $1^{\text {st }}$ ed, New York: Cambridge University Press pp. 49-96.

3. Otsuka K, Ren X (2005) Physical metallurgy of Ti-Ni-based shape memory alloys. Prog Mater Sci 50(5): 511-678.

4. Naresh C, Bose PSC, Rao CSP (2016) Shape memory alloys: A state of art review. IOP Conf Ser Mater Sci Eng 149: 012054.

5. Zhou D, Gao Y, Lai M, Li H, Yuan B, et al. (2015) A review of shape memory alloy research, applications and opportunities. Mater Sci Eng A 56: 1078-1113.

6. Schmahl WW, Khalil-Allafi J, Hasse B, Wagner M, Heckmann A, et al. (2004) Investigation of the phase evolution in a super-elastic NiTi shape memory alloy (50.7 at.\%Ni) under extensional load with synchrotron radiation. Mater Sci Eng A 378(1-2): 81-85.

7. Antonucci V, Martone A (2015) Phenomenology of Shape Memory Alloys. Shape Mem Alloy Eng pp. 33-56.

8. Costanza G, Tata ME (2020) Shape memory alloys for aerospace, recent developments, and new applications: A short review. Materials (Basel) 13(8):1856

9. Caiano A, Ramos AS, Vieira MTF (2015) NiTi Wires Coated by Nanomultilayers - A Solution for Self- healing? Microsc Microanal 21(S5): 11-22.

10. Du Plessis A, Yadroitsev I, Yadroitsava I, Le Roux SG (2018) X-Ray Microcomputed Tomography in Additive Manufacturing: A Review of the Current Technology and Applications. 3D Print Addit Manuf 5(3): 227-247.

11. Hunek M, Pliva Z (2017) Design and optimisation of NiTi pressure gauge. IEEE pp. 1-3.

12. Cavaleiro AJ, Ramos AS, Martins RMS, Fernandes FMB, Morgiel J, et al (2015) Phase transformations in $\mathrm{Ni} / \mathrm{Ti}$ multilayers investigated by synchrotron radiation-based x-ray diffraction. J Alloys Compd 646: 1165-1171. 